\title{
Ecoturismo como alternativa de Desenvolvimento Socioeconômico na Ilha do Cajual, Alcântara (MA)
}

\section{Ecotourism with alternative of socioeconomic developing in the Cajual Island, Alcântara (MA, Brazil)}

Luciana Luisa Chaves Castro, Gabriela Silva Noronha, Manuel Alfredo Araújo Medeiros

\begin{abstract}
RESUMO
O presente artigo busca demonstrar as possibilidades de desenvolver o ecoturismo na llha do Cajual, Alcântara (MA), tendo em vista o seu patrimônio natural que integra atrativos como rios, lagoas, igarapés, praias e manguezais, além de um dos maiores depósitos fossilíferos do Mesozoico brasileiro, incluindo restos de dinossauros. Trata-se de uma pesquisa de caráter qualitativo, por meio de fontes secundárias através de registros, relatórios, publicações, revistas, entre outros, assim como a realização de pesquisa de campo através de um inventário na localidade. Desta maneira, tem como considerações finais que o ecoturismo pode se tornar uma alternativa viável de desenvolvimento socioeconômico para a comunidade, considerando que a mesma se apresenta em condições sociais desfavoráveis nos aspectos de saúde, educação e trabalho. E ainda que o ecoturismo pode contribuir e promover, através de uma maior consciência ambiental, a conservação do ambiente natural de relevante beleza paisagística que revela um importantíssimo patrimônio paleontológico.
\end{abstract}

PALAVRAS-CHAVE: Gestão Ambiental; Ecoturismo; Desenvolvimento Socioeconômico; llha do Cajual.

\section{ABSTRACT}

This paper demonstrates the possibilities of developing ecotourism in the Cajual Island, Alcântara (MA, Brazil), with a view to its natural heritage which includes attractions such as rivers, lakes, streams, beaches and mangroves, and Mesozoic fossiliferous deposits including dinosaurs, one of the largest ever found in Brazil. This is a qualitative research through secondary sources as reports, reports, publications, magazines, etc., as well as an inventory as a result of field research in the locality. Thus, it presents as final considerations the fact that ecotourism may become a socioeconomic alternative of development for the community, considering that it experiences unfavorable social conditions, whether in health issues, education or work. And that ecotourism can contribute and promote, through increased environmental awareness, conservation of the natural environment of relevant scenic beauty that reveals an important paleontological heritage.

KEYWORDS: Environmental Management; Ecotourism; Socioeconomic Development; Cajual Island. 


\section{Introdução}

Através do ecoturismo, pode-se desenvolver alternativas voltadas para a gestão ambiental de áreas com potencial turístico, considerando a relevância e a necessidade de preservação dos aspectos ambientais, e, a possibilidade de envolvimento da comunidade local, estabelecendo uma relação harmônica entre a sustentabilidade ambiental e o desenvolvimento socioeconômico. Configurado como um turismo alternativo e distinto do turismo convencional, o ecoturismo valoriza as vivências diferenciadas em relação à natureza e as comunidades locais. E nesse sentido, o ecoturismo tem também na sua denominação parte de um contexto de turismo responsável por ter seu conceito atrelado a princípios de desenvolvimento sustentável.

Deste modo, o presente artigo busca demonstrar as possibilidades de desenvolver o ecoturismo na Ilha do Cajual, no município de Alcântara (MA), tendo em vista principalmente o seu patrimônio natural com destaque para o seu significativo registro fossilífero do Mesozoico, destacando a ocorrência de dinossauros, um dos maiores já encontrados no Brasil e que atrai pesquisadores e visitantes à localidade.

Para tanto, o objetivo deste estudo é o de apresentar uma proposta de desenvolvimento do ecoturismo para a Ilha do Cajual, baseando-se num inventário de potencialidades da localidade e na necessidade de se desenvolver de maneira responsável o turismo na llha, contribuindo para a melhoria de qualidade de vida dos residentes, e ainda com o mínimo de descaracterização de seus atributos culturais.

Metodologicamente, trata-se de uma pesquisa de caráter qualitativo por meio de fontes secundárias, através da análise de registros, relatórios, publicações, revistas, entre outros, assim como a realização de pesquisa de campo através de um inventário turístico da localidade. Do mesmo modo que também se utilizou de pesquisas referentes a relatórios do projeto de extensão de Educação e Saúde para o Turismo da Universidade Federal do Maranhão, que objetivava analisar a viabilidade do turismo como alternativa de desenvolvimento socioeconômico e os vários projetos de Paleontologia desenvolvidos na região no últimos 20 anos, onde foi percebido o potencial da localidade e da sua população para se envolverem de forma positiva no turismo como uma alternativa real de desenvolvimento local.

O estudo assim relacionado contribuiu para a descrição de resultados que indicam a importância e necessidade de um plano de ações para a implementação da atividade turística na Ilha de Cajual.

Desta maneira, tem se o ecoturismo como um meio de desenvolvimento socioeconômico para a comunidade, considerando que a mesma se apresenta em condições sociais desfavoráveis nos aspectos de saúde, educação e trabalho. E ainda que o ecoturismo pode promover na localidade para construção de novos comportamentos em relação à preservação da beleza paisagística que revela um importantíssimo patrimônio paleontológico.

\section{Ecoturismo e o desenvolvimento local}

Irving (2005) destaca que o turismo, interpretado como a atividade econômica que mais cresce no mundo, passa gradualmente a incorporar novos olhares de planejamento, como resultado de seu potencial gerador de emprego e renda, aporte de benefícios econômicos, sociais e ambientais. 
Ruschmann (2007) e Coriolano (2007) abordam que as políticas e as ações para planejamento turístico devem ser construídas de maneira a otimizar e a promover os benefícios, e a reduzir os custos e os impactos negativos das atividades vinculadas, em sentido amplo da complexidade de cada localidade.

Irving (2002) também aponta a necessidade de se articular a conservação dos recursos naturais com o desenvolvimento de estratégias econômicas de baixo impacto ambiental, entre as quais, o ecoturismo. Isso porque tem papel estratégico no processo de conservação da biodiversidade e geração de benefícios socioeconômicos para as populações locais. Conti e Irving (2010, p.) destacam:

[...] o turismo designado como "responsável" e/ou "inclusivo" (e, particularmente, o ecoturismo nos parques estaduais e federais) emerge, em tese, como alternativa significativa para a minimização dos impactos econômicos sobre a biodiversidade, para a potencialização dos processos de conservação da natureza em áreas de elevada riqueza em fauna e flora e, também, como oportunidade de inclusão das populações locais, com relação à repartição justa dos benefícios decorrentes do uso dessa biodiversidade. Sendo assim, as práticas de ecoturismo vêm sendo interpretadas, em políticas públicas, como alternativas possíveis à conversão das práticas econômicas vigentes nesses territórios, em práticas sustentáveis.

Uma das alternativas de gestão ambiental de áreas com potencial para desenvolvimento do turismo com relevantes aspectos ambientais e possibilidade de envolvimento das comunidades locais pode ser a implementação do ecoturismo, pois tem como base estrutural as premissas relacionadas com 0 conceito de desenvolvimento sustentável, quando prioriza a conservação dos recursos naturais e estabelece uma relação harmônica entre o desenvolvimento socioeconômico e ambiental. Desta forma, o planejamento e a política para o turismo sustentável servem de contexto para a implementação do ecoturismo, estabelecidos pelos princípios do turismo sustentável no que diz respeito ao desenvolvimento econômico, social e desafios da participação efetiva do turismo ambiental na comunidade (OMT, 2002, p.24).

Contudo, é necessário esclarecer que o termo e atividade em si que representa o ecoturismo, não deve ser confundido com o conceito de turismo sustentável. 0 ecoturismo é um segmento que promove o contato mais próximo do turista com o ambiente natural considerando, ainda por vezes, a realização de atividades que envolvem a educação ambiental durante a viagem. Porém, sua prática não leva a crer que já estejam incutidos princípios de sustentabilidade.

O desafio do desenvolvimento sustentável de uma localidade é justamente o crescimento econômico, acompanhado de uma distribuição equilibrada de renda e da devida proteção dos recursos naturais, com vista a assegurar uma qualidade de vida adequada tanto para atuais quanto para futuras gerações, com a participação efetiva da sociedade tanto nas atividades de planejamento como nas de gestão das atividades para o desenvolvimento (BARRETO, 2009).

A participação da comunidade é um desses princípios que devem ser atribuídos como uma forma de distribuição de competências aos atores locais na atividade sustentável do turismo, na medida em que se exerce um importante papel no 
desempenho da conservação da biodiversidade como é ratificado pela Carta de Québec (OMT, 2002).

Entende-se que as "viagens alternativas" são destinadas a lugares que preservem culturas, mesmo diante da homogeneização do turismo, ou mesmo a realização do turismo, em lugares cujo patrimônio natural possa fornecer um cenário excepcional para desempenho atlético e aventureiro, como também para a contemplação de áreas naturais conservadas como lugares e culturas de importância étnica e diferenciada que induzem a prática de ecoturismo (SERRANO, 2004).

Para Western (2005), as origens do ecoturismo podem estar com visitação dos parques mais antigos do mundo, o Yellowstone e o Yosemite, criados nos anos de 1872 e de 1890, respectivamente, nos Estados Unidos, e que concentram um dos maiores ecossistemas no mundo. Assim como as viagens pelo Parque Nacional de Serengeti (WESTERN, 2005) de cerca de $40.000 \mathrm{~km}^{2}$, que fica no norte da Tanzânia e do Quênia, na África.

A origem do termo ecoturismo, como também a representatividade dos seus princípios é algo ainda recente. Mesmo considerando registros já de algum tempo de viagens realizadas por naturalistas como Humboldt, Darwin, Bates e Wallace, pode-se afirmar que suas abordagens não tiveram cunho benéfico e de conservação de áreas naturais, de culturas nativas ou de espécies (CEBALLOS-LASCURÁIN, 2005).

As Diretrizes para uma Política Nacional de Ecoturismo concebida em 1994 através de uma parceria entre o Ministério do Meio Ambiente e a antiga Empresa Brasileira de Turismo (EMBRATUR) ${ }^{1}$, conceitua o ecoturismo como um segmento da atividade turística que utiliza de forma sustentável o patrimônio natural e cultural, incentiva sua conservação e busca a formação de uma consciência ambientalista através da interpretação do ambiente, promovendo o bem-estar das populações (BRASIL, 1994).

Configurado como um turismo alternativo e distinto do turismo convencional, o ecoturismo valoriza as vivências diferenciadas em relação à natureza e as comunidades locais. O ecoturismo tem também na sua denominação parte de um contexto de turismo responsável por ter seu conceito atrelado a princípios de desenvolvimento sustentável, não se afirmando neste sentido, que toda atividade ecoturística seja enquadrada como um turismo sustentável, mas que, entretanto, deveria estar delimitada por princípios sustentáveis já que tem como princípio a preservação de ambientes e culturas locais, como é ratificada por Western (2005),

Ecoturismo, em outras palavras, envolve tanto um sério compromisso com a natureza como responsabilidade social. Essa responsabilidade deve ser assumida também pelo viajante. A expressão "viagem responsável", outra designação para o ecoturismo, envolve objetivos semelhantes. Ecoturismo Society oferece uma definição um pouco mais completa: Ecoturismo é a viagem responsável a áreas naturais, visando a preservar o meio ambiente e a promover o bem-estar da população local (WESTERN, 2005, p.17). 
Mesmo com semelhanças em relação a outros tipos de turismo, como o de natureza, o ambiental, o ecológico, o etnoturismo, o agroturismo, o de aventura e turismo verde, o ecoturismo possui características que o torna um tipo individualizado de turismo e distinto dos demais segmentos que já possuem outros parâmetros conceituais e práticos, não devendo assim ser confundido.

$\mathrm{Na}$ visão de Western (2005) se for adotado um conceito muito amplo que abrange uma variedade de segmentações ligadas ao turismo em áreas naturais, o ecoturismo corre o risco de perder sua essência. É sugerido pelo mesmo autor que o ecoturismo deve provocar e satisfazer o desejo de aliar natureza e potencial turístico visando a conservação e o desenvolvimento, impedindo impacto negativo sobre a ecologia, a cultura e a estética dos lugares visitados.

O ecoturismo como parte essencial do desenvolvimento sustentável deve ser promovido por um viés multidisciplinar, contando ainda que se sugere um planejamento cauteloso e a realização de medidas que sirvam de suporte a diretrizes e regulamentos rigorosos, garantindo um funcionamento estável entre setores, governos, empresas privadas, comunidades locais e ONG's de significativa importância nesse processo (CEBALLOS-LASCURÁIN, 2005).

Com o ano do Ecoturismo e a realização da Cúpula Mundial do Ecoturismo em Québec, no Canadá, em 2002, foi produzida a Carta de Québec, instituindo as diretrizes para a implementação do ecoturismo no contexto do desenvolvimento sustentável. A Cúpula destacou como parte de suas discussões, a importância do turismo comunitário aplicado ao ecoturismo, requerendo uma maior organização política por parte da comunidade, compreendendo que os projetos ecoturísticos comunitários se apresentam como uma proposta de combate à pobreza, às injustiças e à destruição do meio ambiente. $E$ esse processo não deve se limitar a boas intenções, ao passo que há uma necessidade de um trabalho especializado de entendimento sobre o mercado turístico e a dinâmica da comunidade (OMT, 2002).

O envolvimento da comunidade em ações de defesa do lugar qualifica o desenvolvimento do turismo na localidade, de modo a ser um fator fundamental para a proteção dos recursos naturais, assim como um revés que viabiliza a implementação do turismo com a capacidade de incorporar anseios da comunidade de cunho preservacionista. Porém, para que isso venha a se concretizar, Fernandes et al (2011) afirma que a comunidade deve adquirir o entendimento da relevância do meio ambiente natural no desenvolvimento de práticas comunitárias que viabilize o bem-estar e não venha a ameaçar seus modos de vida.

Desta forma, o ecoturismo surge como um aliado na gestão ambiental de áreas de relevância ambiental, ao mesmo tempo em que fortalece a apropriação das áreas naturais, dinamiza as economias locais e incrementa os recursos financeiros para a manutenção destas áreas. O desafio consiste, no entanto, em desenvolver um turismo responsável e integrado à diversidade sociocultural, aos conhecimentos tradicionais e à conservação da biodiversidade.

\section{O desenvolvimento do ecoturismo na Ilha do Cajual, Alcântara (MA)}

O município de Alcântara atualmente constitui-se num dos polos de expressiva potencialidade turística do Estado do Maranhão, pelo seu conjunto arquitetônico, pelas suas manifestações culturais e pelas suas belezas naturais, além de abrigar a mais moderna base de lançamento de foguetes da América Latina, o Centro de 
Lançamento de Alcântara, que desenvolve projetos de alta tecnologia. Localizada a 22 km de São Luís, na porção mais oeste da baía de São Marcos, Alcântara é considerada uma Cidade Monumento pelas suas ruínas, casarões antigos, sua beleza natural e diversas manifestações culturais. A cidade foi tombada pelo Patrimônio Histórico Nacional, em 1948, pelo grande significado histórico. A culinária alcantarense é também um elemento de atrativo turístico, representado por pratos à base de frutos do mar (peixes, camarões e demais mariscos). Os doces de espécie e os licores de caju, murici, jenipapo e goiaba, constituem tradicionais iguarias típicas do município.

Por outro lado, Alcântara subaproveita o seu potencial turístico em prol do seu desenvolvimento socioeconômico, principalmente por problemas como precariedade da infraestrutura de apoio: rede hoteleira, restaurantes e entretenimento. Tais aspectos contribuem para o pequeno fluxo turístico na cidade, em decorrência do pouco tempo de permanência do turista, visto que os atrativos existentes na sede não necessitam de mais que um dia para serem apreciados.

Uma alternativa que poderá aumentar o fluxo de turistas e sua permanência (pernoite) é a criação de roteiros ecoturísticos. Alcântara apresenta opções de uma rota ecológica, com povoados com praias, ilhas detentoras de belezas cênicas, comunidades com predisposição para trabalhar o turismo. Neste contexto, 0 desenvolvimento do ecoturismo na llha do Cajual apresenta significativo potencial. A ilha é caracterizada por uma paisagem tropical ainda selvagem, com lagoas de água doce, praias, falésias e igarapés, povoados por uma fauna e flora variadas, conservando muitos aspectos de sua natureza selvagem, onde se destacam os ninhais de diversas aves residentes (como guarás, garças e taquiris) e os bandos de maçaricos migratórios que frequentam as praias durante alguns meses do ano (RODRIGUES, 2000).

A ilha do Cajual, em Alcântara, possui uma área de 6 mil hectares, rica em mangues, peixes e crustáceos. Localizada no extremo oeste da baía de São Marcos, nos limites do município de Alcântara, e a cerca de 25 km de São Luís (Figura 1). Pertence à Área de Proteção Ambiental das Reentrâncias Maranhenses, possuindo uma das maiores densidades de aves costeiras. A costa com domínio de planícies de maré e manguezais, que vai do Maranhão ao Pará, onde se localiza a ilha, é o segundo lugar da América do Sul em concentração de aves migratórias.

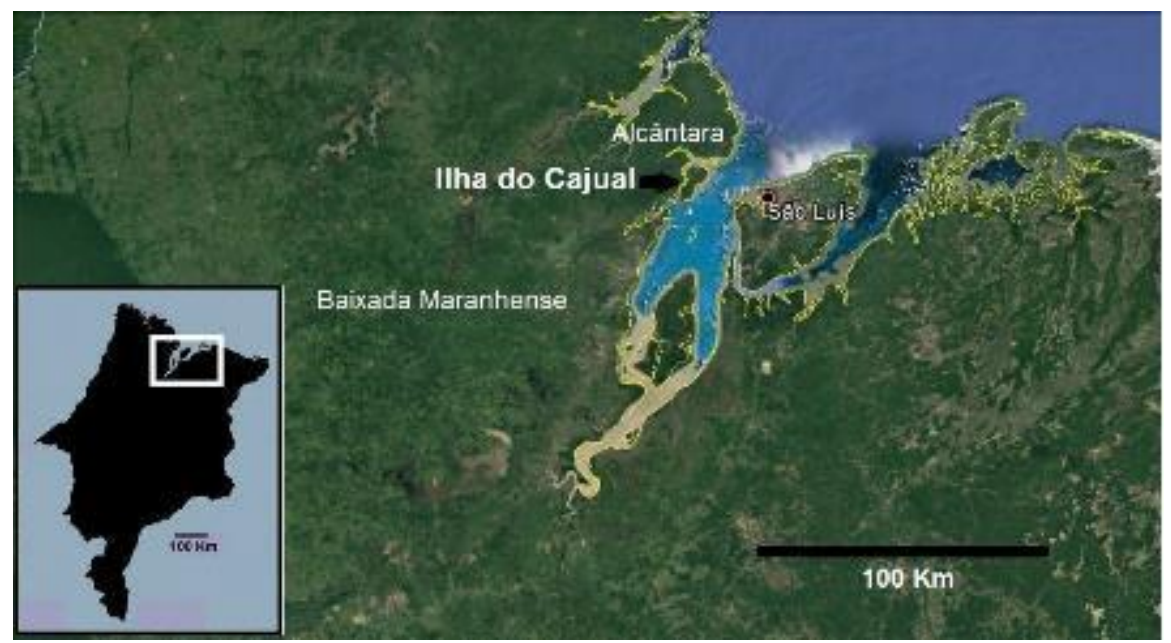

Figura1: Mapa de localização da llha do Cajual, no norte do Maranhão. Fonte: Google Earth.

Figure 1: Location map of Cajual Island, in north of Maranhão. Source: Google Earth. 
Nesse ponto de encontro das mais variadas espécies de aves é possível contemplar um dos mais ricos espetáculos naturais. Cerca de 150 mil indivíduos entre aves costeiras, distribuídos em 15 espécies, podem ser encontrados anualmente no Golfão Maranhense. Várias espécies são residentes e se reproduzem na Ilha do Cajual. Entre elas, está uma espécie ameaçada de extinção por pressão de caça, o guará - Eudocimus ruber. Esta bela espécie de ave, de pernas longas e finas, de porte próximo ao de uma garça, chama atenção pelo contraste de suas penas vermelhas com o verde dos manguezais da llha.

De acordo com estudos sobre a potencialidade turística da localidade, diagnosticou-se que o ecoturismo é uma alternativa viável de desenvolvimento socioeconômico e gestão ambiental para a conservação dos recursos naturais. Porém, o desafio configura-se na situação que as comunidades que residem na llha do cajual apresentam. Ali, nota-se um quadro social desfavorável nos aspectos de saúde, educação e trabalho, caracterizado por grande número de pessoas com baixa escolaridade e, consequentemente, poucas chances no mercado de trabalho.

A população residente na ilha forma uma comunidade remanescente de escravos oriundos das antigas fazendas de engenho do município de Alcântara, com aproximadamente 80 famílias, distribuídas em pequenos povoados relativamente dispersos. Desenvolvem uma economia de subsistência, principalmente pesca, pequenas roças de milho, mandioca, arroz e banana. As condições de moradias são precárias; não existe abastecimento de água pública e tratada. Ao invés disso, são furados poços, tipo cacimbas, com condições inadequadas para consumo humano. Não existe energia elétrica, a escola só tem ensino fundamental precário; não existe atenção aos cuidados com a saúde das comunidades, o que problematiza ainda mais a situação de qualidade básica de vida para essa população.

Por outro lado, existem alternativas que podem contribuir para a mudança deste quatro negativo de qualidade de vida. $\mathrm{Na}$ ilha, existe potencial para a prática do ecoturismo, com belezas paisagísticas das praias e manguezais. Além deste fato, complementando o potencial ecoturístico da llha do Cajual, em 1994, pesquisadores da Universidade Federal do Rio de Janeiro (UFRJ) e da Universidade Federal do Maranhão (UFMA) realizavam prospecção geológoica e paleontológica na ilha, quando o geólogo Francisco Corrêa Martins encontrou um depósito fossilífero em rochas do Mesozoico, incluindo grande conjunto de ossos de dinossauros. O sítio se revelaria um dos maiores do Brasil para esta época.

Com as descobertas destes fósseis do Período Cretáceo, presentes em algumas localidades da llha do Cajual (CORRÊA MARTINS 1996; MEDEIROS et al. 1996; MEDEIROS 2001; MEDEIROS; VILAS BÔAS 1999, MEDEIROS; SCHULTZ 2001; VILAS BÔAS et al. 1999), notou-se um aumento de visitantes na região nos anos subsequentes, com interesse científico ou por mera curiosidade, visto que o achado foi amplamente divulgado na imprensa nacional e internacional. A existência de grande quantidade de restos de dinossauros que viveram há cerca de 95 milhões de anos atrás, e do registro dos processos envolvidos com a separação do continente sul-americano do africano, nesta mesma época, registrado nas rochas que afloram nas falésias litorâneas (ROSSETTI 1996, 1997a, b; ROSSETTI 1998; ROSSETTI; TOLEDO 1996; ROSSETTI; TRUCKENBRODT, 1997; HOLZ et al. 2001) aumentaram também o interesse turístico pela ilha.

Todos estes atributos conferem à llha do Cajual uma posição privilegiada dentre os locais de alto potencial para exploração turística no Maranhão, com uma 
evidente vocação para a exploração do ecoturismo, que é um dos segmentos que mais cresce em interesse.

O presente estudo tem como objetivo oferecer uma proposta de desenvolvimento do ecoturismo na Ilha do Cajual, baseando-se nas potencialidades tanto da localidade quanto dos seus moradores, na necessidade de se implementar de maneira responsável o turismo contribuindo para a melhoria de qualidade de vida de residentes, e ainda com o mínimo de descaracterização de seus atributos culturais, e na urgência de se garantir um meio de preservar o patrimônio biológico da localidade, pelo próprio potencial que ele possui de atrair recursos.

Como metodologia de trabalho para o desenvolvimento de roteiros turísticos na Ilha de Cajual, tem-se como proposta a caracterização dos principais pontos de interesse turístico enunciados abaixo:

- Manguezais - um rico ecossistema que sustenta a reprodução de grande quantidade de espécies animais, desde invertebrados a vertebrados. A grande quantidade de matéria orgânica que existe nos manguezais é responsável pela sustentação de inúmeros organismos adaptados as suas condições extremas. A lama dos manguezais é povoada por um enorme número de organismos invertebrados que, por sua vez, servem de alimento para animais vertebrados, principalmente as aves. Por isso, os bosques de mangue são verdadeiros santuários de pássaros, como as garças, os taquiris e guarás.

- Matas - a llha do Cajual é em boa parte dominada por matas em estado natural. Destacam-se os bosques de babaçu, à semelhança da mata dos cocais, no interior do estado. Os babaçuais interdigitam-se com a vegetação mais costeira, de plantas arbustivas e arbóreas de pequeno porte, criando uma paisagem tropical muito bonita. Este tipo de ambiente abriga uma fauna variada de aves e mamíferos, alguns exóticos, como os mucuris e coandús, que fazem da ilha um paraíso de vida selvagem.

- Praias e marés - toda a parte leste da llha do Cajual é dominada por praias arenosas e lamosas. São praias com extensas planícies de maré, ou seja, com um amplo soalho inundado, que pode ter uma zona inter-maré com mais de 600 metros de amplitude. Estas planícies ocorrem como consequência da topografia do terreno, pouco inclinado, e pela amplitude das marés, que estão entre as maiores do Brasil, podendo atingir mais de 6,5 metros de altura. Este fenômeno curioso da subida e descida das enormes marés do norte maranhense é bem marcado nas praias da llha do Cajual, e sem dúvida despertam interesse dos visitantes.

- Aves - a fauna de aves residentes e migratórias da llha do Cajual oferece um dos mais belos vislumbres da vida selvagem do norte maranhense. Os maçaricos migratórios que frequentam as praias lamosas da ilha alguns meses por ano, fugindo do rigoroso inverno do Canadá (ver Rodrigues 2000), e os ninhais de garças, guarás e taquiris, nos luxuriantes manguezais do norte da ilha (ver CUNHA et al. 1994; RODRIGUES 1995; MARTÍNEZ 1998; MARTÍNEZ; RODRIGUES, 1999) são um poderoso atrativo para os turistas que visitam a região. São particularmente sensacionais as revoadas de milhares destas aves que se dirigem para seus ninhos no final das tardes, vindas de pontos mais internos do Golfão Maranhense, onde passam o dia alimentando-se.

- Falésias - O extremo leste da llha do Cajual é dominado por falésias íngremes, a maioria com mais de 10 metros de altura (algumas podem chegar a mais de 
20 metros). Elas são resultado da erosão marinha que age sobre os morros costeiros. As falésias da baía de São Marcos são formadas principalmente por rochas antigas, de um período do tempo geológico conhecido como mesoCretáceo (que data de cerca de 95 milhões de anos). A equipe de geólogos do Museu Emílio Goeldi, de Belém, da UFRJ, Rio, UFMA, São Luís, e UFRGS de Porto Alegre vêm estudando estas rochas há vários anos e já publicaram uma grande quantidade de informações científicas sobre elas (CORREAA MARTINS, 1996; ROSSETTI 1996, 1997a, b; ROSSETTI; TOLEDO 1996, ROSSETTI; TRUCKENBRODT, 1997; HOLZ et al. 2001). As estruturas observadas nas rochas de Alcântara e llha do Cajual mostram os processos geológicos envolvidos com a separação do continente sul-americano e africano, justamente no meso-Cretáceo. É possível identificar marcas que testemunham terremotos resultantes das forças tectônicas que agiam no litoral maranhense em uma época em que o Atlântico sul ainda era estreito e raso, e a África estava ainda próxima da América do sul. Estas informações são de óbvio interesse de cunho turístico, porque contam parte da história remota do norte-nordeste do Brasil, e do continente sul-americano, como um todo.

- Fósseis - Desde 1994, a llha do Cajual vem se destacando na imprensa nacional e estrangeira, como uma importante localidade fossilífera. Um grupo de pesquisadores vem estudando o rico documentário de animais e plantas fossilizados do Período Cretáceo, época em que os dinossauros dominavam a Terra. Vários grupos de dinossauros, peixes e plantas já foram identificados (CORRÊA MARTINS, 1996; MEDEIROS 2001; MEDEIROS; VILAS BÔAS 1999; MEDEIROS; SCHULTZ 2001; MEDEIROS et al. 1996; VILAS BÔAS et al., 1999), e hoje o resultado destas pesquisas fez com que o sítio fossilífero Laje do Coringa, na ilha, seja um dos principais atrativos turísticos da localidade.

- Cultura local - As comunidades que habitam a llha do Cajual, que têm seu meio de vida na pesca, criação e agricultura de subsistência, são em sua maioria compostas por negros, descendentes de escravos que encontraram um lugar pacato e de natureza quase intocada, na ilha. A maioria dos colonizadores da localidade migrou de Alcântara nos séculos XIX e XX e estabeleceu pequenos povoados, cuja rotina inclui o cultivo e processamento da mandioca e outros produtos agrícolas, a criação de bovinos, suínos e galináceos e a pesca nas praias da ilha. Estas comunidades até hoje cultuam ritos africanos sincretizados com a doutrina cristã, como por exemplo, o tambor de crioula. A cultura local da comunidade receptora constitui um atrativo valioso para os visitantes.

A proposta de trilhas para acesso aos principais pontos turísticos identificados parte do princípio de que o ponto de base dos visitantes será o principal povoado, chamado Tijuca. Desta forma, pode-se aproveitar os acessos já utilizados pelos seus moradores, não havendo a necessidade de abertura de novas trilhas, e assim, não desencadeando danos ambientais pelo desmatamento.

As trilhas estabelecidas para visitação na ilha visam dar ao turista uma visão ampla e detalhada de todos os elementos naturais e culturais da localidade, e efetivamente coloca os moradores como os principais envolvidos na receptividade (gastronomia, artesanato, guias locais, dentre outras atividades). Os roteiros planejados são os seguintes:

- Trilha 1: Porto grande - Tijuca (distância: $2 \mathrm{Km}$ ): O porto Grande é o local de desembarque. A trilha leva dele, que é o ponto mais ocidental da ilha, ao interior, onde ficam os povoados. A vegetação característica é de 
mangue e mata úmida cortada por um canal, já próximo às povoações. É uma trilha sem maiores dificuldades de percurso. Leva diretamente ao povoado Tijuca, onde estará montada a infraestrutura para a permanência do grupo.

- Trilha 2: Povoado Tijuca - praia (distância: 1,4 Km): a trilha tem aproximadamente menos de 1 metro de largura; em alguns trechos, por conta da erosão ocasionada pelas chuvas, pode chegar a mais de 1 metro. Alguns pequenos trechos, próximos à lagoa do Juçaral, são acidentados, apresentando sulcos e ravinas. Passando da lagoa, encontra-se uma ponte de madeira, que está sobre uma área alagada de 1,5 metros de profundidade, no verão. A vegetação local é formada por um babaçual que ocorre ao longo de quase toda a trilha. Próximo à praia, a vegetação adquire características de restinga, com pés de murici e caju, em solo arenoso. Esta trilha é uma opção interessante para o turista, por levá-lo a um contato direto com a natureza, expondo belezas ao longo de todo o trajeto, até a bela praia do Juçaral. São recomendados roupas leves e uso de tênis ou bota para maior conforto.

- Trilha 3: Praia - Laje do Coringa (distância: 2,1 Km): esse percurso é feito pela praia, onde pode-se apreciar a planície de maré com amplitude de quase um quilômetro e o relevo dominante na região, com falésias e restingas. A visita à Laje do Coringa (sítio fossilífero) só pode ser efetuada na baixa mar, quando estará emersa. A laje representa um dos mais densos sítios fossilíferos do Brasil, registrando a Era Mesozoica, quando os dinossauros dominaram a Terra. Essa trilha oferece ao visitante a oportunidade de usufruir da paisagem praieira e de obter conhecimentos sobre o registro das rochas e dos fósseis, favorecendo o turismo aliado ao estudo científico. O vestuário recomendado é o de roupas leves de praia.

- Trilha 4: Laje do Coringa - ninhal dos guarás (distância: 4 km): a mais longa das trilhas é toda percorrida pelas praias do litoral oriental da ilha. Seu percurso dá-se ao longo da paisagem costeira, dominada por restinga, manguezais luxuriantes e igarapés quase intocados, com trechos de mangue seco. Leva ao extremo norte da Ilha do Cajual, onde pode-se apreciar a vista de Alcântara, há cerca de $5 \mathrm{Km}$ mais ao norte, e da Ilha do Livramento, mais próxima. Neste ponto, pode-se observar, no final da tarde, as revoadas de milhares de guarás, com suas penas escarlate contrastando com o por do sol.

Com base na operacionalização das trilhas, pode-se estabelecer as etapas da implementação do Ecoturismo para Ilha do Cajual como sugere-se a partir das seguintes orientações:

1ำ Etapa: Mobilização de Instituições e comunidade

- Apresentação do potencial ecoturístico da llha do Cajual;

- Realização de reuniões objetivando a constituição de parcerias entre iniciativas públicas e privadas e organizações sociais para a interlocução e coresponsabilidade para implementação da proposta;

- Estabelecimento de estratégias locais e estaduais; 
- Mapeamento das ações de cada entidade parceira com o objetivo de promover o diálogo e otimizar os recursos disponíveis e buscar novas parcerias em função das necessidades e prioridades locais.

20 Etapa: Estudo de Viabilidade da implementação do ecoturismo

- Indicar áreas prioritárias para implementação do ecoturismo, combinando atrativos naturais e culturais para elaboração de roteiros integrados, com base em consideração de logística e mercado;

- Avaliar potenciais (aptidões) e interesses dos moradores das comunidades em tornarem-se empreendedores das atividades ligadas ao ecoturismo;

- Identificação de artesões e artesanatos nas comunidades;

- Demonstrar a estimativa de número e natureza de empregos gerados diretos e indiretos na implementação do ecoturismo;

- Identificar tipos de capacitações necessárias para atender demandas de empreendimentos atuais e futuros para a implementação do ecoturismo;

- Identificar a logística operacional do roteiro, incluindo acesso, traslado, hospedagem, alimentação, locais de venda de produtos regionais e artesanato.

3o Etapa: Elaboração do Plano Estratégico Participativo do Ecoturismo para a Ilha do Cajual:

Será respaldado por meio da percepção e demandas das comunidades envolvidas - com a elaboração de documento que aponta o potencial das localidades, o que está bom, o que precisa melhorar, e propostas de ações futuras para a implementação do produto ecoturístico da llha do Cajual etc;

\section{Conclusões}

O desafio do desenvolvimento sustentável de uma localidade tem como objetivos crescimento econômico, com distribuição equilibrada de renda, proteção dos recursos naturais, com vista a assegurar uma qualidade de vida melhor tanto para atuais quanto para futuras gerações. O planejamento com a participação efetiva das comunidades na construção das atividades e gestão para o seu desenvolvimento são essenciais para que as mesmas tenham capacidade de autonomia individual e coletiva de caráter emancipatório, tornando-se protagonistas de todo seu processo de desenvolvimento local.

A alternativa de gestão ambiental pode ser a implementação do ecoturismo, pois tem como base de estrutura as premissas relacionadas com o conceito de desenvolvimento sustentável, quando prioriza a conservação dos recursos naturais e estabelece uma relação harmônica entre o desenvolvimento socioeconômico e ambiental.

A exemplo de muitas localidades no Maranhão, a llha do Cajual, em Alcântara, é um verdadeiro santuário natural de lagoas, igarapés, praias e manguezais, onde as pessoas têm a oportunidade de observar as belezas naturais da região ainda em estado quase selvagem. Pode-se observar as revoadas de milhares de aves de várias espécies, como os guarás, as garças, os taquiris e maçaricos; conhecer um dos mais importantes jazigos fóssilíferos do Brasil - a Laje do Coringa, onde várias espécies de dinossauros já foram coletadas e estudadas. Ser hipnotizado pelos 
misteriosos ritos afros, cultuados pela religião dos moradores da ilha, e que são uma herança da época da escravidão.

Mas para que toda essa riqueza não se perca, é necessário que a prática do turismo seja acompanhada de medidas de conservação dos ambientes naturais e resguardo da cultura local. A própria prática do ecoturismo pode ser alternativa de melhoria de vida para as populações da Ilha do Cajual e estimular a conservação dos recantos selvagens e jazigos fossilíferos, que são o principal atrativo para os turistas que frequentarão a localidade. Todo o processo de envolvimento da comunidade da Ilha do Cajual na exploração turística tem que ser precedido e acompanhado por um trabalho de conscientização da população local, para promover a conservação dos atributos de interesse turístico, e para prevenir os efeitos detrimentais que o contato dela com turistas das mais diferentes culturas poderia causar.

As visitas periódicas de pessoas à ilha, acompanhadas de profissionais envolvidos com pesquisa científica e guias locais treinados, poderão representar um importante incremento na renda das comunidades locais, uma vez que não só as pessoas envolvidas diretamente com os passeios turísticos, mas também aquelas que exerçam alguma atividade agrícola, pesqueira e artesanal, cuja produtividade possa servir para alimentação dos visitantes ou mesmo ser adquirida como souvenir, seriam beneficiadas.

Nessas condições, estaremos incentivando a consciência ambiental e cultural, tanto da comunidade quanto dos turistas, pois a prática de preservação traz benefícios, perpetuando assim os atrativos naturais e culturais da localidade para as gerações futuras e trazendo o desenvolvimento sustentável com geração de renda, implicando na melhoria da qualidade de vida da população da Ilha do Cajual.

O desenvolvimento do ecoturismo na llha do Cajual pode aproveitar as habilidades da sua população nas diversas formas de trabalho gerada por meio do turismo, pois pode envolver seus moradores na hospedagem, alimentação, locais de venda de artesanato para o turista, além de vários outros tipos de atividades. Constatou-se que envolver esses moradores no chamado efeito multiplicador do turismo poderá desencadear benefícios relacionados à qualidade de vida, com aumento da autoestima da sua população, para busca de melhores indicadores de saúde, educação e condições dignas de moradia, trabalho e renda. Observou-se que desenvolver o ecoturismo não é só uma questão de renda, é possibilitar as condições dignas de sobrevivência de sua população, que se encontra em estado de abandono pelas Instituições públicas responsáveis, que não aproveitam toda uma vocação natural da ilha para o ecoturismo em prol do desenvolvimento socioeconômico.

Desta forma, o desenvolvimento do ecoturismo na Ilha do Cajual, viabilizando a visitação aos sítios paleontológicos e santuários naturais da localidade, e o contato com a peculiar cultura local, de forma planejada, que não venha a ameaçar os mesmos e sim garantir sua conservação e dar à população da ilha a oportunidade de melhorar seu nível de vida sem causar impactos indesejáveis, possibilitaria promover ecoturismo como alternativa de desenvolvimento local e preservação ambiental. 


\section{Referências bibliográficas}

BARRETO, M. Planejamento responsável do turismo. Campinas, SP: Papiros.111p., 2009.

BRANCO, C.E. O meio ambiente para pequenas empresas de construção civil e suas práticas de gestão ambiental. 2.ed. Fortaleza; Banco do Nordeste do Brasil. 161p., 2012.

BRASIL. EMBRATUR. Diretrizes para uma política nacional do ecoturismo. Brasília: EMBRATUR, 1994.

CEBALLOS-LASCURÁIN, H. O Ecoturismo como um fenômeno mundial. In: LINDBERG, K.; HAWKINS, D.E. Ecoturismo: um guia para planejamento e gestão. São Paulo: Editora Senac São Paulo, 2005. p. 23-29.

MARTINS, F.J.C., 1996. Levantamento de aspectos geológicos da parte setentrional da ilha de São Luís e áreas adjacentes. Dissertação de Mestrado. PPG - Geologia, UFRJ, Rio de Janeiro. 98p.

CUNHA, A.H.F., RODRIGUES, A.A.F.; MARTÍNEZ, C. Desenvolvimento de filhotes de Taquiri, Nyctanassa violacea (CICONIIFORMES: ARDEIDAE), na ilha do Cajual, Alcântara, Maranhão, Brasil. Monografia de Graduação, Depto. de Biologia UFMA, São Luís. 26p. 1994.

FERNANDES, R.; et al. Ecoturismo de base comunitária: uma realidade ou uma utopia. PASOS. Revista de Turismo y Patrimônio Cultural. v.9, n. 2, 2011. Disponível em: <http://www.pasosonline.org/Publicados/9211/PS0211 17.pdf>. Acesso em: 20 jan. 2012.

HOLZ, M.; MEDEIROS, M.A.; SCHULTZ, C.L. Tafocenoses de vertebrados formando resíduos transgressivos - o exemplo do sítio fossilífero "Laje do Coringa" do Neo-cretáceo da Bacia de São Luís no norte do Brasil. Boletim de Resumos do XVII Congresso Brasileiro de Paleontologia, Rio Branco,. Pg. 36, 2001.

LEFF, H. Saber Ambiental: sustentabilidade, racionalidade, complexidade, poder. 8aㅡ. Ed. Petropólis, RJ: Vozes, 2011.

MARTÍNEZ, C. Ecología trófica y reproductiva de seis especies de Ciconiiformes en um sistema de manglar. Tese de Doutorado. Universitat de Barcelona, Barcelona, 1998.

MARTÍNEZ, C.; RODRIGUES, A.A.F. Breeding biology and status of a Scarlet lbis (Eudocimus ruber) population in Northern Brazil. Journal of Field Ornithology, v.70, n.4, pp. 558-566, 1999.

MEDEIROS, M.A. A Laje do Coringa (Ilha do Cajual, Bacia de São Marcos, MA): conteúdo fossilífero, bioestratinomia, diagênese e implicações na paleobiogeografia do Mesocretáceo do nordeste brasileiro. Tese de Doutorado. IGEO - UFRGS, Porto Alegre. 134p.., 2001.

MEDEIROS, M.A.; MARTINS, F.C., SILVA JR.; F.R., PONTES, H.; VILLAS BÔAS, I. A laje do Coringa (Ilha do Cajual - MA): depósitos conglomeráticos fossilíferos contendo restos de dinossauros. Revista de Geologia, v.9, pp.123-129., 1996.

MEDEIROS, M.A.; VILAS BÔAS, I. A Laje do Coringa: uma paleocomunidade continental do Cenomaniano do Nordeste do Brasil. Boletim de Resumos do Congresso Brasileiro de Paleontologia 16,: 1999, pp.70-71. 
MEDEIROS, M.A.; SCHULTZ, C.L. Uma paleocomunidade de vertebrados do Cretáceo Médio, Bacia de São Luís. In: ROSSETTI, D.F.; GÓES, A.M.; TRUCKENBRODT, W. (eds.). O Cretáceo na Bacia de São Luís - Grajaú. Museu Emílio Goeldi, Belém: 2001, pp.209-221.

ORGANIZAÇÃO MUNDIAL DE TURISMO-OMT. Declaração de Manila para um Turismo Mundial. Manila, Filipinas: Organização Mundial de Turismo, 2002. Disponível em: <www.marcionami.adm.br/pdf/gestao/Declaracao Manila.pdf $>$. Acesso em: 17 abr. 2011.

ORGANIZAÇÃO MUNDIAL DE TURISMO-OMT. Carta de Quebec. Quebec, Canadá: Organização Mundial do Turismo, 2002. Disponível em: $<$ http://www.ecobrasil.org.br/publique/media/declaracao de quebec.pdf $>$. Acesso em 17 abr. 2011.

RODRIGUES, A.A.F. Ocorrência da reprodução de Eudocimus ruber na ilha do Cajual, Maranhão, Brasil (Ciconiiformes: Threskiornithidae). Ararajuba v.3, pp.6768., 1995.

RODRIGUES, A.A.F. Seasonal abundance of Neartic shorebirds in the Gulf of Maranhão, Brazil. Journal of Field Ornithology, v. 71, n.4, pp.665-675, 2000.

ROSSETTI, D.F. Sequence stratigraphic significance of two estuarine valley fills: the Upper Itapecuru Formation in the São Luís Basin, Northern Brazil. Acta Geologica Leopoldensia, v.43, n.19, pp.111-125, 1996.

ROSSETTI, D.F. Internal architecture of mixed tide- and storm-influenced deposits: an example from the Alcântara Formation, northern Brazil. Sedimentary Geology v.114, pp.163-188, 1997 a.

ROSSETTI, D.F. Seismic-induced disturbances in late Cretaceous rocks of the São Luís Basin, Maranhão State, Brazil. Boletim do Museu Paraense Emílio Goeldi, Série Ciências da Terra v.9, pp.3-20. 1997 b.

ROSSETTI, D.F. Facies architeture and sequential evolution of an incised-valley estuarine fill: the Cujupe Formation (Upper Cretaceous to Lower Tertiary), São Luís Basin, Northern Brazil. Journal of Sedimentary Research, v.68, n.2, pp.299-310, 1998.

ROSSETTI, D.F.; TOLEDO, P.M. Cenomanian climate in northern Brazil: evidences from sedimentary features in the Upper Itapecuru Formation. Anais da Academia Brasileira de Ciências 68. Suplemento, 1, pp.139-147, 1996.

ROSSETTI, D.F.; TRUCKENBRODT, W. Revisão estratigráfica para os depósitos do Albiano-Terciário Inferior (?) na Bacia de São Luís (MA), norte do Brasil. Boletim do Museu Paraense Emílio Goeldi (Série Ciências da Terra) v.9, pp.29-41, 1997.

SEIFFERT, M.E. Gestão ambiental: instrumentos, esfera de ação e educação ambiental. São Paulo; Atlas, 2010.

SERRANO, C. Poéticas e políticas das viagens. In: SERRANO, C.; BRUHNS, H.; LUCHIARI, M. (Org.) Olhares contemporâneos sobre o turismo. 2 ed. Campinas, SP: Papirus, 2004.

VILAS BÔAS, I; CARVALHO, I.S.; MEDEIROS, M.A.; PONTES, H. Dentes de Carcharodontosaurus (Dinosauria, Tyrannosauridae) do Cenomaniano, Bacia de São Luís (Norte do Brasil). Anais da Academia Brasileira de Ciências, v.71, n.4, pp.846-847, 1999. 
WESTERN, D. Como definir o ecoturismo. In: LINDBERG, K.; HAWKINS, D.E. Ecoturismo: um guia para planejamento e gestão. São Paulo: Editora Senac São Paulo, 2005. p. 14-22.

\section{Nota:}

${ }^{1}$ Atualmente denominada de Instituto Brasileiro de Turismo (EMBRATUR).

Luciana Luisa Chaves Castro: Universidade Federal do Maranhão, São Luís, MA, Brasil.

E-mail: Ilccturismo@yahoo.com.br

Link para o currículo Lattes: http://lattes.cnpq.br/2016742598994785

Gabriela Silva Noronha: Universidade Federal do Piauí, Teresina, PI, Brasil.

E-mail: gabrielanoronha@hotmail.com

Link para o currículo Lattes: http://lattes.cnpq.br/7927652461505166

Manuel Alfredo Araújo Medeiros: Universidade Federal do Maranhão, São Luís, MA, Brasil.

E-mail: alf@ufma.br

Link para o currículo Lattes: http://lattes.cnpq.br/1059798585946068

Data de submissão: 29 de abril de 2015

Data de recebimento de correções: 25 de julho de 2016

Data do aceite: 25 de julho de 2016

Avaliado anonimamente 